\title{
Normal coronary arteriogram An avoidable test?
}

\author{
C ILSLEY, A STOCKLEY, D CLITSAKIS, C LAYTON
}

From the Cardiac Department, The London Chest Hospital, The National Heart Hospital, and the Department of Medical Physics, Southend Hospital

SUMmARY Between 10 and $20 \%$ of coronary arteriograms in patients with chest pain show normal vessels, often in association with a history of "atypical" angina. Conventional non-invasive tests are inaccurate in this group of patients compared with those with classical angina. This study prospectively evaluates combined 12 lead exercise electrocardiography and thallium-201 scintigraphy as a screening test in patients with atypical angina in order to determine whether normal arteriograms are avoidable in this important subgroup of patients presenting with chest pain.

Sixty seven consecutive patients with atypical angina underwent both maximal exercise testing and thallium scintigraphy before coronary arteriography. Chest pain during exercise was a poor predictor of coronary disease in this group. Eleven (16\%) had abnormal arteriography, with the sensitivity of exercise and thallium tests being $45 \%$ and $73 \%$, respectively. When both tests were applied the predictive accuracy for normal coronary arteries was $96 \%(54 / 56)$ and that for the presence of coronary disease was $82 \%(9 / 11)$.

If coronary arteriography was withheld in patients in whom both the exercise test and thallium scintigraphy were negative, the number of normal coronary arteriograms could be reduced with only a very small risk of failing to detect individuals with coronary disease.

Coronary arteriography is widely used in the assessment of patients with chest pain though a significant proportion undergo this investigation solely to establish whether or not coronary artery disease is present. At the London Chest Hospital, for example, excluding patients with valvular heart disease and cardiomyopathy, $380(16.6 \%)$ of 2292 coronary arteriograms performed in the years 1977-79 were normal. Within this group there was a preponderance of patients with atypical angina. There remains a need for non-invasive techniques that can accurately assess the presence or absence of disease in this difficult group of patients, thereby diminishing the use of diagnostic coronary arteriography, and avoiding the small risk involved in such a procedure.

Our early experience of exercise electrocardiography and exercise thallium-201 scintigraphy in patients with coronary disease suggested that a combination of these methods might provide a useful screening test. ${ }^{1}$ The predictive accuracy of a single diagnostic test diminishes as the disease prevalence within the population under study falls. ${ }^{2}$ It is only by the combination of two

Accepted for publication 14 June 1982 tests, ideally looking at different but related indices for ischaemia, that a high predictive accuracy could theoretically be maintained. This study was established to assess the ability of combined 12 lead exercise testing and thallium-201 scintigraphy to predict those patients with normal coronary arteriography within a group presenting with atypical angina.

\section{Subjects and methods}

Sixty seven consecutive patients complaining of atypical angina were studied. They comprised 56 men and 11 women aged 29 to 62 years (mean age 49 years). Patient selection was prospective before the results of any non-invasive test were known. Patients with classical angina (exercise related chest pain, relieved by rest and trinitrin and exacerbated by cold or emotional stress) were excluded, as were those with a history of previous myocardial infarction or definite non-cardiac chest pain. The remaining patients had "atypical" angina defined as follows: the chest pain was thought to be anginal by the referring physician though either there was no apparent relation of pain to exercise or it was not immediately relieved (within 10 minutes) 
by rest or trinitrin. None of the patients had been investigated, other than by a resting electrocardiogram, before referral. Routine treatment consisted of a beta blocking agent in 48 (72\%), long acting nitrates in 22 $(33 \%)$, and a calcium antagonist in $13(19 \%)$. Fifty nine $(88 \%)$ were taking trinitrin as necessary.

\section{EXERCISE TEST}

Each patient underwent maximal 12 lead treadmill exercise electrocardiography using a modified Bruce protocol. ${ }^{3}$ The 12 leads were the same as those recorded in a standard electrocardiogram. Recordings were made on an automated three channel machine at rest, at the end of each three minute stage, at peak exercise, and at two minute intervals during the recovery period until the electrocardiogram returned to the resting state. Blood pressure was monitored at the end of each stage. End points for the test were chest pain, dyspnoea, achievement of predicted maximum heart rate (220-age), or inability to continue exercise because of fatigue or calf claudication.

\section{THALLIUM SCANNING}

Thirty seconds to one minute before the attainment of peak exercise $2 \mathrm{mCi}$ of thallium-201 was injected via an antecubital vein. Five minutes after exercise the patient was positioned in front of a Searle LFOV gamma camera or a Nuclear Enterprises MkV HR gamma camera, interfaced with a Searle Scintiview processing system or a Varian V76 computer, respectively. Scans were obtained in the $45^{\circ}$ left anterior oblique, left lateral, and anterior views with 300000 counts recorded for each frame. The images were processed by a combination of nine point smoothing and background subtraction. Abnormal perfusion was defined by segmental uptake of less than $50 \%$ that found in the most active myocardial segment.

\section{INTERPRETATION OF RESULTS}

All patients underwent coronary angiography with multiple views obtained using the Sones technique. Lesions of $70 \%$ or more stenosis in a major coronary artery were considered significant. Exercise electrocardiography, thallium scanning, and coronary angiography were all examined and reported separately without knowledge of the other results.

\section{Results}

Eleven (16\%) of the 67 patients had an abnormal coronary arteriogram. Six patients had disease in one artery and only two had triple vessel disease. All the women had normal coronary arteriography.

The resting electrocardiogram was abnormal in 25 (37\%). Nineteen of these had normal coronary arteriography. The resting electrocardiographic abnormalities, which were largely minor, are detailed in Table 1. No patients had evidence of prior myocardial infarction on the basis of pathological $Q$ waves. The only patient with ST segment depression at rest had left ventricular hypertrophy, secondary to longstanding hypertension. An abnormal resting electrocardiogram was not associated with the presence or absence of coronary disease.

Table 1 Resting electrocardiographic abnormalities in 67 patients with atypical angina

\begin{tabular}{ll}
\hline Electrocardiographic finding & No. of patients \\
\hline Bundle-branch block & $2\left\{\begin{array}{l}1 \text { left } \\
1 \text { right }\end{array}\right.$ \\
Left ventricular hypertrophy & 1 \\
Poor R wave progression & 2 \\
T wave "abnormalities" & 20 \\
\hline
\end{tabular}

\section{EXERCISE TEST}

Although chest pain on exertion was a feature of the history of most patients in this study, only seven $(10 \%)$ developed chest pain during the exercise test, and six of these had normal coronary arteriography.

Seven $(10 \%)$ patients had an unequivocally positive exercise electrocardiogram when using $0 \cdot 1 \mathrm{mV}$ horizontal or down sloping ST segment depression from rest at $80 \mathrm{~ms}$ after the $\mathrm{J}$ point as the diagnostic criterion. With $0.2 \mathrm{mV}$ of ST depression the number of positive tests was six. Five $(71 \%)$ of the seven patients with exercise-induced ST depression had coronary artery disease. Of the remaining 60 patients, 51 achieved a maximal or near maximal heart rate for age without significant ST segment depression, with six (12\%) subsequently proven to have coronary artery disease and thus falsely negative exercise tests. In the remaining nine patients, the level of exercise was low (peak heart rate less than $105 / \mathrm{min}$ ) because of the patients' unwillingness to proceed further. No evidence of ST depression was found and the patients were classified as negative before coronary arteriographic results were available, which confirmed that none had coronary disease.

Twelve $(20 \%)$ of the 60 patients with negative exercise tests had horizontal or down sloping ST depression of greater than $0.05 \mathrm{mV}$ but less than 0.1 $\mathrm{mV}$, thus just failing to fulfil the "positive" criterion. Two of these had bundle-branch block and one had left ventricular hypertrophy and resting ST depression. None had abnormal coronary arteriography.

THALLIUM SCINTIGRAPHY

Satisfactory thallium scintigrams were obtained in all cases even in those with a low level of exercise. The latter were interpreted despite high background levels 
of activity. Nine (13\%) had an abnormal scan, of whom eight had coronary disease. Three patients with coronary disease had normal scintigraphy, though all three had single vessel involvement. All five of those with double or triple vessel disease had abnormal scintigraphy. The remaining 55 patients had normal scintigraphy.

COMBINED EXERCISE AND THALLIUM RESULTS When the results of both tests were combined for each patient nine $(82 \%)$ of 11 with significant disease were identified. In the two patients with abnormal tests but normal coronary arteriography, one had both exerciseinduced ST depression and abnormal scintigraphy and the other an abnormal exercise electrocardiogram only. There was no apparent cause of the ST depression.

Both patients with coronary disease and negative tests had single vessel disease, in one an isolated occlusion of the posterior descending branch of a dominant right coronary artery and in the other a single $70 \%$ stenosis of a lateral circumflex branch. All 12 of those showing $0.05 \mathrm{mV}$ to $0.09 \mathrm{mV} \mathrm{ST}$ depression had normal thallium scintigraphy and coronary arteriography.

\section{Discussion}

Patients with atypical angina are less likely to have underlying coronary artery disease than those with classical angina pectoris. ${ }^{4}$ While normal coronary arteriography does not exclude a cardiac cause for the pain, it does provide a good long term prognosis for an individual even in the presence of continuing symptoms, ${ }^{5}$ and will modify advice that may be given concerning the patient's occupation and life style. In the most experienced hands coronary arteriography, whether performed by brachial or femoral techniques, carries a small but definite mortality and morbidity, and it is desirable to restrict arteriography to those most likely to show coronary artery stenosis. A non-invasive test that reliably identifies patients with normal coronary arteriograms would be clinically valuable. This study was performed to test the ability of combined maximal 12 lead exercise electrocardiography and thallium-210 scintigraphy in this respect.

Only $16 \%$ of patients in this study had coronary artery disease. None of the 11 women and $20 \%$ of the men had disease. The male preponderance perhaps reflects an unwillingness of physicians to refer women with atypical pain while having a higher level of suspicion for the presence of coronary disease in men presenting with the same symptoms. Though thallium scintigraphy had a sensitivity of $73 \%$ and a specificity of $98 \%$ which was superior to the exercise electrocardiogram by itself in this study (Table 2), both tests are subject to error if used in isolation. ${ }^{6}$

Normal thallium scintigraphy was particularly helpful in the 12 patients in this study who had definite but less than $0 \cdot 1 \mathrm{mV} \mathrm{ST}$ segment depression. ${ }^{78}$

Nine patients failed to exercise to at least $85 \%$ of the predicted heart rate maximum and thus perhaps had unreliable, though negative, non-invasive tests. None had coronary disease. A proportion of patients do find exercise tests formidable and are unwilling to perform an adequate test. Such patients must be assessed on an individual basis and either have a second exercise test or proceed to arteriography. Patients with angina who are unable to exercise to rapid heart rates are more likely to have coronary disease even without ST segment change, ${ }^{9}$ but these data cannot be used automatically to justify arteriography in patients with atypical angina.

Patient selection for this study is of critical importance in assessing its value. Patients were evaluated prospectively on the basis of the clinical presentation and resting electrocardiogram without any non-invasive testing before inclusion in the study. We deliberately excluded those with a high likelihood of disease (typical angina and prior myocardial infarction) and the study group was obtained consecutively from routine new patient referrals from general practitioners and nonspecialist physicians. In retrospect, if only those patients with positive (11 patients) or equivocal tests (the 12 patients with $0.05 \mathrm{mV}$ to $0.09 \mathrm{mV}$ ST depression) underwent angiography then all those with multivessel disease were identified, with the prevalence of disease in this selected group being significantly higher than in the remaining patients (prevalence 39\% $(9 / 23)$ versus $5 \%(2 / 44), p<0 \cdot 0125)$. The clinical impact of such an approach can only be assessed from the results of a larger scale study than this one. Nevertheless the results are encouraging and suggest that

Table 2 Results of each investigation and combined interpretation *

\begin{tabular}{|c|c|c|c|c|c|c|c|c|}
\hline Test & True positive & False negative & True negative & False positive & Sensitivity & Specificity & $P A+$ & $P A-$ \\
\hline $\begin{array}{l}\text { Thallium-201 } \\
12 \text { lead exercise } \\
\text { Thallium or exercise }\end{array}$ & $\begin{array}{l}8 \\
5 \\
9\end{array}$ & $\begin{array}{l}3 \\
6 \\
2\end{array}$ & $\begin{array}{l}46 \\
45 \\
45\end{array}$ & $\begin{array}{l}1 \\
2 \\
2\end{array}$ & $\begin{array}{l}73 \% \\
45 \% \\
82 \%\end{array}$ & $\begin{array}{l}98 \% \\
96 \% \\
96 \%\end{array}$ & $\begin{array}{l}89 \% \\
71 \% \\
82 \%\end{array}$ & $\begin{array}{l}94 \% \\
88 \% \\
96 \%\end{array}$ \\
\hline
\end{tabular}

* Excluding the nine patients with inadequate exercise (peak heart rate $105 / \mathrm{min}$ ).

Sensitivity, $\%$ positive/number with coronary disease; Specificity, $\%$ negative/number with normal coronary arteries; PA+, predictive accuracy of a positive test; $\mathrm{PA}-$, predictive accuracy of a negative test. 
about half of the normal coronary arteriograms currently performed are perhaps avoidable.

The coronary arteriograms were assessed only for the presence of fixed lesions and no attempt was made to detect coronary artery spasm. The object of this study was to determine whether a normal coronary arteriogram could be predicted, not to establish the cause of the presenting symptom. Ergometrine provocation testing was abandoned in our unit in 1979 in view of the risk of myocardial infarction and death resulting from such tests. ${ }^{10} \mathrm{We}$ have not excluded spasm, therefore, as a cause of the pain in some of our patients.

The relatively poor predictive accuracy of the exercise electrocardiogram in patients with atypical angina is in accord with previous studies. ${ }^{4} 11$ Exercise is an integral part of thallium scintigraphy and both electrocardiogram and scintigram provide complementary information in the overall assessment of an individual patient with chest pain. This study has confirmed that if coronary arteriograms are withheld in those with normal non-invasive tests there is only a small risk to detect an individual with coronary stenosis.

\section{References}

1 Clitsakis D, Layton CA, Battersby W, Johns M, Stockley AV. Effect of stenosed and occluded coronary arteries on immediate and late myocardial uptake of thallium-201. Br Heart f 1981; 46: 186-9.

2 Epstein SE. Implications of probability analysis on the strategy used for non-invasive detection of coronary artery disease. Am $\mathcal{F}$ Cardiol 1980; 46: 491-9.

3 Bruce RA. Exercise testing of patients with coronary heart disease. Ann Clin Res 1971; 3: 323-32.
4 Weiner DA, Ryan TJ, McCabe $\mathrm{CH}$, et al. Correlations among history of angina, exercise stress testing ST segment response and prevalence of coronary artery disease in the coronary artery surgery study (CASS). $N$ Engl f Med 1979; 301: 203-5.

5 Kemp HG, Jr Vokonas PS, Cohn PF, Gorlin R. The anginal syndrome associated with normal coronary arteriograms. Report of a six year experience. Am $\mathcal{J}$ Med $1973 ; 54: 735-42$.

6 Verani MS, Marcus ML, Razzak MA, Ehrhardt JC. Sensitivity and specificity of thallium-201 perfusion scintigrams under exercise in the diagnosis of coronary artery disease. $\mathcal{F ~ N u c l ~ M e d ~ 1 9 7 8 ; ~ 1 9 : ~ 7 7 3 - 8 2 . ~}$

7 Botvinick EH, Taradash MR, Shames DM, Parmley WW. Thallium-201 myocardial perfusion scintigraphy for the clinical clarification of normal, abnormal and equivocal electrocardiographic stress tests. Am $\mathcal{F}$ Cardiol 1978; 41: 43-51.

8 Kattus AA. Exercise electrocardiography: recognition of the ischemic response, false positive and negative patterns. Am f Cardiol 1974; 33: 721-31.

9 Chaitman BR, Bourassa MG, Wagniart P, Corbara F, Ferguson RJ. Improved efficiency of treadmill exercise testing using a multiple lead ECG system and basic hemodynamic exercise response. Circulation 1978; 57: 719.

10 Buxton A, Goldberg S, Hirshfeld JW, et al. Refractory ergonovine-induced coronary vasospasm: importance of intracoronary nitroglycerine. Am $\mathcal{F}$ Cardiol 1980; 46: 329_ 34.

11 Borer JS, Brensike JP, Redwood DR, et al. Limitations of the electrocardiographic response to exercise in predicting coronary-artery disease. $N$ Englf $M$ Med 1975; 293: 367-71.

Requests for reprints to Dr C Layton, Cardiac Department, The London Chest Hospital, Bonner Road, London E2 9JX 